
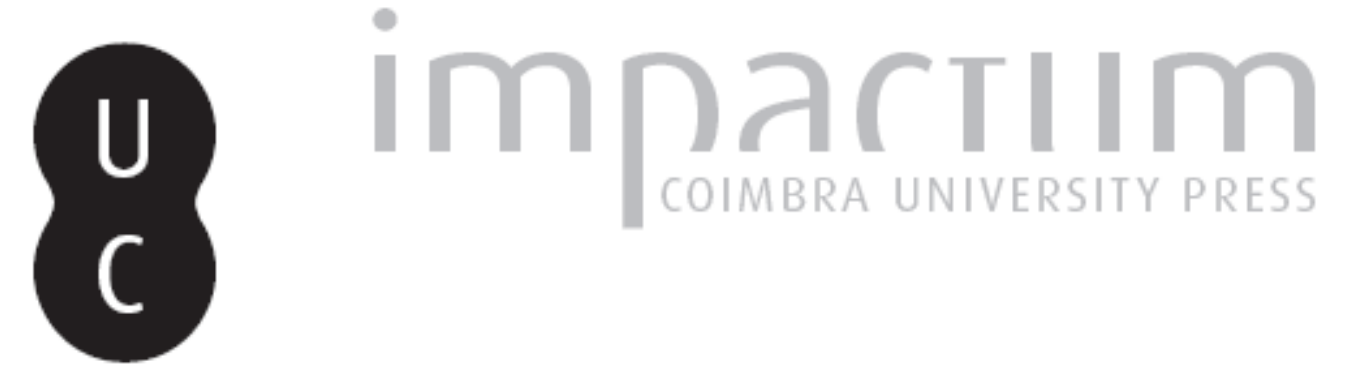

\title{
Darwin e as raças humanas
}

\section{Autor(es): Vieira, António Bracinha}

Publicado por: CIAS - Centro de Investigação em Antropologia e Saúde

URL persistente:

URI:http://hdl.handle.net/10316.2/28659

DOI:

DOI:http://dx.doi.org/10.14195/2182-7982_27_5

Accessed : $\quad$ 26-Apr-2023 12:32:51

A navegação consulta e descarregamento dos títulos inseridos nas Bibliotecas Digitais UC Digitalis, UC Pombalina e UC Impactum, pressupõem a aceitação plena e sem reservas dos Termos e Condições de Uso destas Bibliotecas Digitais, disponíveis em https://digitalis.uc.pt/pt-pt/termos.

Conforme exposto nos referidos Termos e Condições de Uso, o descarregamento de títulos de acesso restrito requer uma licença válida de autorização devendo o utilizador aceder ao(s) documento(s) a partir de um endereço de IP da instituição detentora da supramencionada licença.

Ao utilizador é apenas permitido o descarregamento para uso pessoal, pelo que o emprego do(s) título(s) descarregado(s) para outro fim, designadamente comercial, carece de autorização do respetivo autor ou editor da obra.

Na medida em que todas as obras da UC Digitalis se encontram protegidas pelo Código do Direito de Autor e Direitos Conexos e demais legislação aplicável, toda a cópia, parcial ou total, deste documento, nos casos em que é legalmente admitida, deverá conter ou fazer-se acompanhar por este aviso.

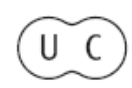




\section{Antropologia Portuguesa}

Volume $26-27 \cdot 2009-2010$

Departamento de Antropologia | Universidade de Coimbra

DARWINISMO:

revisitações, propostas, problemas 


\section{Darwin e as raças humanas}

\section{António Bracinha Vieira}

Centro de Filosofia das Ciências da Universidade de Lisboa

Universidade Nova de Lisboa, Portugal

vieyrantonio@hotmail.com

Resumo Neste artigo analisamos, a partir dos próprios textos, a posição teórica de Darwin e as suas dúvidas taxonómicas em relação ao problema da unidade versus diversidade humana. Em contraste com a atitude não racista de Wallace, Darwin supôs encontrar entre as populações humanas dos vários continentes diferenças tais que hesitou entre dividir a humanidade em 'raças' ou em 'espécies'. Enquanto os critérios morfológicos lhe mostravam diversidade, os comportamentos, sobretudo as emoções e as suas máscaras mímico-emotivas, revelaram-lhe a unidade do Homem.

Palavras-chave Homem; raças; espécie; emoções; máscaras mímicas.

Abstract In this paper we analyse the theoretical position of Darwin and his taxonomic uncertainties concerning the problem of the unity versus diversity of mankind, quoting fragments of his own texts. Contrasting with Wallace's non racist perspective, Darwin found between the human populations of the several continents so deep differences that he hesitated in classifying them as 'races' or 'species'. While the morphological criteria convinced him of the great human diversity, the study of emotions and their expressive mimic masks offered him the evidence of the unity of Man.

Key words Man; races; species; emotions; mimic masks.

O famoso livro The Origin of Species by Means of Natural Selection, comummente abreviado sob a denominação The Origin of Species, tinha como subtítulo, ou melhor, como título alternativo, The Preservation of Favoured Races in the Struggle for Life. Demasiado longo para o gosto actual e politicamente incorrecto para os tempos presentes, este outro título, tão fortemente malthusiano, deixou de ser citado na maior parte dos casos, e mesmo em edições inglesas recentes da Origem. Este mal-entendido de Darwin com o futuro - ele, que tantas e tão fundamentadas predições fez que a história das ideias veio a reconhecer e celebrar - merece uma breve análise. 
De facto, Darwin não encontrou critérios nem argumentos para classificar o Homem. Não foi só o ambiente de racismo pseudo-científico prevalecente entre os naturalistas e antropólogos do século XIX que o influiu: foi também, e sobretudo, quer-nos parecer, a noção nebulosa de espécie que se lhe deparava e a ausência do conceito de especiação (que só a teoria genética poderia explicitar). Não deixa de ser surpreendente que, em relação às outras espécies, o problema não o tenha impedido de ponderar criticamente os dados em jogo - e quando John Gould the falou nas diferentes espécies, e mesmo géneros, dos tentilhões das Galápagos com base nos exemplares que trouxera naturalizados da viagem do Beagle, Darwin foi como que iluminado por essa informação e partiu sem constrangimentos para a formulação da sua teoria.

Perante a entidade $o$ Homem e a sua origem e taxonomia, foi ele próprio tomado de preconceito e não viu o que, mesmo sem genética, era visível aos seus olhos de naturalista experiente e mais arguto do que qualquer outro no seu tempo. Claro que os fósseis de antepassados humanos eram escassos e polémicas as suas interpretações (também elas envolvidas pelo ambiente racista que rondava as sociedades de anatomia e de antropologia da época, dentro e fora de Inglaterra). Faltavam, também, métodos e técnicas de datação que permitissem medir a profundidade do tempo. Darwin tomou o Homem - do qual não quis definir os limites e a fronteira - como uma forma antiga, atendendo à variação aparente dos tipos humanos que se lhe deparava, e conjecturou que a sua longa evolução deixara para trás raças desfavorecidas na tal luta pela vida.

Lendo-o hoje, torna-se-nos claro que tomou os povos selvagens que conheceu por resíduos desses antepassados remotos impregnados de 'animalidade' e que a selecção natural em breve destruiria: as 'raças' periféricas deparavam-se-lhe como relíquias, atestando de estados anacrónicos da humanidade mais remota. Quando a ideia de selecção natural lhe surgiu como explicação plausível e mecanismo activo da evolução, algumas memórias do que conhecera dos 'primitivos actuais' vieram ilustrá-la e levaram-no a interessantes interpretações evolucionistas. Ouçamo-lo, a este respeito, em The Descent of Man:

«Mal pode haver dúvidas de que descendemos de bárbaros. Não mais esquecerei o espanto que senti ao ver pela primeira vez um grupo de fueguinos num local bravio e anfractuoso da costa, porque acudiu-me logo ao pensamento 
a reflexão seguinte: tais foram os nossos antepassados. Os homens estavam completamente nus e cobertos de pinturas, com longos cabelos emaranhados; as bocas espumavam de excitação, a mímica era selvagem, assustada e desconfiada. A custo disporiam de alguns saberes (any arts), e como animais selvagens viviam do que podiam alcançar.» (Darwin, 1871).

Quase quarenta anos antes, em 17 de Dezembro de 1832, fizera esse encontro insólito, descrito por ele no Diário do Beagle. De facto, nesse dia, ao dobrar a entrada norte da baía do Bom Sucesso, a tripulação do brigue avistou fueguinos: «Um grupo de fueguinos olháva-nos, empoleirado num pico selvagem sobre o mar, cercado por floresta. Enquanto passávamos, levantaram-se e, ondulando as capas de pele (que os cobriam), soltaram um formidável brado.» No dia seguinte, Fitzroy enviou a terra um bote para comunicar com os fueguinos, levando a bordo Darwin e alguns marinheiros:

«Foi o mais curioso e singular espectáculo que jamais presenciei. Sem ele, não teria acreditado quão radical é a diferença entre um selvagem e um homem civilizado, maior do que entre um animal bravio e um animal domesticado. (...) As suas atitudes eram abjectas, a expressão desconfiada, surpreendida e mesmo atónita. (...) A linguagem nem merece que se lhe chame articulada. (...) Se as vestes e a aparência eram miseráveis, a sua maneira de viver ainda o era mais. (...) O comportamento global mostrava uma estranha mescla de espanto e imitação. (...) Creio que, se o mundo fosse (exaustivamente) pesquisado, não se poderia encontrar grau inferior de homem (lower grade of man)». E, a 20 de Janeiro, perante um novo encontro com outro grupo do mesmo povo: «A sua aparência era tão estranha que a custo parecia de habitantes terrestres.» (Darwin, 1988).

A razão crítica do homem de ciência é aqui claramente obnubilada pela emoção. Os juízos valorativos, fortes e numerosos, que Darwin produz, bem o provam. Contrastam singularmente com a atitude de Wallace relativa a povos sem escrita entre os quais permanecera: «Ao partir (...) acreditei que, globalmente, a minha estadia entre este povo simples e de boa natureza (good-natured) foi causa de prazer e benefício para ambas as partes.» (Wallace, 1863). Não há dúvida de que a população de Aru tivera mais contactos com a civilização do que os habitantes da Terra do Fogo. Mas também quanto aos índios da Amazónia Wallace mostrara uma disposição 
benévola, admirando como tinham desenvolvido o engenho necessário para sobreviverem em meio tão adverso.

A leitura de The Descent of Man revela-nos a perplexidade e as hesitações de Darwin sobre a diversidade dos grupos humanos existentes no mundo do seu tempo. «Não há dúvida - escreve - de que as várias raças, quando cuidadosamente comparadas e medidas, diferem muito umas das outras - como na textura dos cabelos, as proporções relativas de todas as partes do corpo, a capacidade dos pulmões, a forma e volume do crânio, e até as circunvoluções do cérebro.» (Darwin, 1871: 259). Tentando dar caução à ancestralidade humana, causa de diversidade, compara as várias espécies de ectoparasitas das populações humanas dos vários continentes, concluindo que são diferentes - mas sem analisar o facto de que essas populações estão espalhadas por todos os continentes, com excepção da Antárctica.

Noutro ponto do livro, dá por provada a menor fertilidade dos cruzamentos inter-raciais (excepto na ilha Pitcairn, onde ingleses, os amotinados da Bounty, se tinham cruzado com as indígenas) e a menor vitalidade dos mulatos, e escreve: «Mas os pais dos mulatos não podem situar-se na categoria de espécies extremamente diferentes.» (Darwin, 1871: 265). Na dúvida, acrescenta: «Pode ser judiciosamente sugerido que, a ser restabelecida a perfeita fertilidade das raças cruzadas do Homem, isso não nos impeça de as classificar como espécies distintas.» (Darwin, 1871: 267). E, logo adiante, retoma a justificação de tão estranha ideia, contrária ao próprio conceito de espécie: «Vemos assim que um naturalista pode sentir-se plenamente justificado a classificar as raças humanas como espécies distintas, ao verificar que se distinguem por muitas diferenças de estrutura e constituição, sendo algumas importantes (...) e pode então admitir que a fertilidade cruzada entre as raças ainda não foi totalmente provada e, ainda que provada, não seria prova absoluta (contra) a sua identidade específica.» (Darwin, 1871: 268).

Quem ouvimos aqui não é o naturalista atento e objectivo, pronto a abandonar uma explicação se os factos e os conceitos o contradissessem. Entretanto, perante a evidência, Darwin concede a existência de uma enorme população mestiça no Brasil; mas não atenta no gradiente imperceptível das cores da pele (para não referir outros traços) que acompanha as variações de latitude, fenómeno exemplar em África, mas observável nos outros continentes, e a custo admite o papel adaptativo da melanina na protecção da pele humana: «Se a protecção da pele humana das queimaduras (solares) tem suficiente importância para acentuar a gradação das peles negras por 
selecção natural, disso sou incapaz de ajuizar.» (Darwin, 1871: 303). Não se refere às castas da Índia, perfeitamente inter-férteis após cerca de quatro mil anos de rigorosa separação regida por interditos culturais. Mas acede a afirmar que «o mais pesado dos argumentos contra tratar as raças humanas como espécies distintas é que têm gradações entre elas (...) e é impossível descortinar entre elas claros traços distintivos.» (Darwin, 1871: 270). E acrescenta: «Se (um naturalista) for prudente, acabará por reunir todas as formas gradativas numa só espécie, dizendo a si mesmo que não tem o direito de denominar objectos que não pode definir.» (Darwin, 1871: 271). Eis as suas hesitações perante este tema delicado, cujos indícios aparentemente discrepantes o deixam perplexo.

Ora, a discussão da taxonomia humana que empreende, apoiada sobre estas observações contraditórias e a partir destas hesitações, levam-no a conclusões surpreendentes e equívocas - não apenas à luz dos conhecimentos e clarificações da ciência de hoje, mas com base nos seus próprios dados e argumentos. Assim, por exemplo, afirma: «Facto interessante é que as raças antigas (de homens) mostram com frequência estruturas que se assemelham mais às dos animais precedentes do que as raças modernas. Uma causa básica parece ser que as raças antigas ficam, na longa linhagem da descendência, mais perto dos seus remotos progenitores, semelhantes a animais (their remote animal-like progenitors).» (Darwin, 1871: 32). E compreendemos como, para Darwin, os fueguinos, entre outros grupos humanos, seriam remanescentes de ramos ancestrais de uma humanidade primitiva muito remota, estruturalmente diferentes dos homens civilizados, não somente pela cultura como pela natureza biológica ${ }^{1}$.

Oscilando entre atribuir aos grupos humanos o estatuto de 'raças' ou o de 'espécies', acaba por optar, com reservas, por designá-los como subespécies: «Se o homem primitivo (...) merece o nome de homem, isso dependerá da definição adoptada. Numa série de formas sucessivamente gradativas, desde alguma criatura simiesca (ape-like) até ao homem como hoje existe, será impossível fixar o ponto exacto em que o termo 'homem' deve ser usado. Mas este é assunto de somenos importância. Por isso, volta

\footnotetext{
${ }^{1}$ Entretanto, e com a maior argúcia, suscita um forte argumento contra o que viria a ser a 'hipótese multi-regional' da evolução humana, ao escrever: «Pareceria incrível que os descendentes modificados de dois organismos, uma vez que divirjam um do outro de maneira acentuada, possam mais tarde convergir a ponto de levarem a nova aproximação de identidade na sua organização global.» (Darwin, 1871: 275).
} 
a ser de pouco relevo se as raças humanas são assim designadas, ou antes classificadas como espécies ou subespécies; mas o último termo parece-me o mais apropriado.» (Darwin, 1871: 279-280). E algures, reforçando esta ideia: «Parece que o termo subespécies pode ser usado aqui com propriedade ${ }^{2} . »$ (Darwin, 1871: 271-271).

O que parece querer enfatizar é o excesso de distância física e 'moral' entre os grupos humanos, tanto étnicos como linguísticos. Pondera se o conceito de 'raça' será suficiente para exprimir essas diferenças, que se lhe afiguram desmedidas: mas como argumentos decisivos, entre eles o da fertilidade dos mestiços, se erguem perante o seu juizo crítico como uma barreira, opta pelo nível taxonómico da subespécie, que concilia a radicalidade das diferenças com a evidência da inter-fertilidade. Vemos, por outro lado, a importância que para Darwin ainda toma o pensamento lamarckista de scala naturae, sobretudo nesse troço problemático que conduziria dos antropóides ao Homem. Não precisa o conceito de espécie ${ }^{3}$, o que o aproxima de Lamarck, nem concede à espécie o rigoroso estatuto de comunidade interfértil separada dos congéneres como critério de definição. Tão-pouco formula o conceito claro de especiação, exterior à ideia de gradiente evolutivo, de resto inabarcável e informulável sem o concurso da genética.

Contudo, num ponto do ensaio sobre as raças humanas contido em The Descent of Man, concede à cultura um surpreendente papel de recuperação das mentalidades, que, em breves períodos, seria capaz de transformar o mais extremo selvagem no civilizado por excelência - o sujeito inglês victoriano. Di-lo logo depois de descrever os diferentes traços morais e temperamentais das 'raças': «Fui constantemente tocado, enquanto vivi com fueguinos a bordo do Beagle (referia-se aos indivíduos que tinham sido levados para Inglaterra e depois devolvidos ao seu povo de origem), pelos inúmeros traços caracteriais indicando semelhanças entre o seu espírito e o nosso; e o mesmo aconteceu com um negro de puro-sangue, do qual aconteceu ter sido íntimo.» (Darwin, 1871: 276).

De resto, Darwin atribui às 'raças' certos universais expressivos de comunicação, e em geral de comportamento - aparentemente mais cons-

${ }^{2}$ A perplexidade de Darwin reflecte e anuncia provavelmente a controvérsia actual entre os sistematas que preferem ou um modelo de lumping ou de spliting.

${ }^{3}$ «É trabalho ínvio decidir deste assunto (que formas humanas devem ser tidas como espécies), até que alguma definição do termo espécie seja globalmente aceite.» (Darwin, 1871: 272). 
tantes e válidos, para a delimitação de uma condição humana, do que os traços morfológicos. Assim, por exemplo, escreve: «Isto (a universalidade de certos comportamentos) é revelado (...) pela mútua compreensão dos gestos linguísticos (mutual comprehension of gesture-language), pela mesma expressão dos seus conteúdos e pelos mesmos gritos inarticulados, quando excitados pelas mesmas emoções.» (Darwin, 1871: 277). Por outro lado, analisa a invenção separada e paralela do arco e das flechas por grupos humanos, nos vários continentes: «Este facto só pode ser explicado pelas mesmas capacidades inventivas e o mesmo poder mental das várias raças.» (Darwin, 1871: 277). É surpreendente que não se detenha na comparação das diversas indústrias paleolíticas, já bem documentadas na sua época e dispondo de sólida tipologia (obtida por antropólogos franceses, como Edouard Lartet, que Darwin cita com frequência a outros títulos), para fundar patamares evolutivos da humanidade. Provavelmente, a ciência da Pré-história, demasiado francesa ${ }^{4}$, não era apreciada pelos naturalistas ingleses da geração de Darwin.

Ao valor taxonómico do comportamento se referirá no seu grande livro seguinte, publicado um ano depois, The Expression of the Emotions in Man and Animals (Darwin, 1872), livro extraordinário - pela ousadia com que um naturalista aborda domínios então tratados por psicólogos e neurofisiologistas - e de extrema modernidade, que funda historicamente as disciplinas da etologia e da etologia humana (sem as denominar), estruturando para elas as bases teóricas e as linhas gerais do método, que outros retomaram à sua sombra, mas apenas nos anos 1970, ou seja, um século depois (Ekman e Friesen, 1977; Eibl-Eibesfeldt, 1979). Assim procura encontrar no comportamento fundamentação complementar para a evolução. Porque cedo observa que os comportamentos evoluem de modo adaptativo e sofrem os efeitos da selecção natural, tal como as estruturas morfológicas e às vezes em interacção com elas (evolução morfo-comportamental); além disso, os comportamentos podem ser descritos, comparados e referidos tanto a uma matriz filogenética originária (base da etologia objectivista) como ao seu processamento neurológico subjacente (base da hoje chamada neuro-etologia). Todos estes espaços heurísticos são delineados neste livro com mestria.

\footnotetext{
${ }^{4}$ A própria tipologia das ferramentas paleolíticas, organizada por arqueólogos franceses, atribuira aos vários módulos denominações (que ainda prevalecem) referentes a locais de França, país onde mais tarde apareceriam muitas das grutas paleolíticas ornamentadas.
} 
No que se refere ao Homem, analisa sobretudo os comportamentos mímico-expressivos das emoções que, ponderadamente, supõe de carácter endógeno, sendo alguns deles universais de comportamento com carácter inato, e por isso ancorados na história natural da espécie. Neste contexto, Darwin enviou um questionário a diversos correspondentes espalhados pelo mundo, visando obter um inquérito transcultural da relação possível entre certas emoções e as mímicas correspondentes. «As respostas referem-se a várias das mais separadas e selvagens raças humanas. (...) Segue-se, da informação assim obtida, que o mesmo estado de espírito é expresso ao longo do mundo com notável uniformidade; e este facto é interessante em si mesmo, como evidência da estreita semelhança existente entre a expressão corporal e a respectiva disposição mental em todas as raças da humanidade.» (Darwin, 1872: 24). Ou seja, para ele, é o comportamento que comprova e resgata a unidade do Homem.

Refere-se à sua antiga atenção a este assunto e às suas primeiras observações dizendo-lhe respeito, logo em 1838, e escreve: «Nesse ano, eu estava já inclinado a acreditar no princípio da evolução, ou da deriva das espécies a partir de outras e precedentes formas.» (Darwin, 1872: 25). Eis o fundamento da nova ciência (que virá a ser a etologia) no âmbito da sua teoria: «Quem admitir, num plano geral, que a estrutura e os hábitos de todos os animais evoluiram gradualmente, olhará para o tema da expressão a uma luz nova e interessante.» (Darwin, 1872: 19). Por isso - diz - «pareceu-me de grande importância esclarecer se os mesmos gestos e expressões prevalecem, como frequentes vezes se afirma sem prova, em todas as raças da humanidade, em especial nas que tiveram pouco convívio com os europeus. Desde que os mesmos movimentos e posturas corporais exprimam as mesmas emoções em raças humanas separadas, poderemos inferir daí, com alta probabilidade, que tais expressões são genuínas - isto é, inatas ou instintivas. Enquanto que as expressões e os gestos adquiridos individualmente durante fases precoces da vida diferem provavelmente entre as diversas raças, de maneira semelhante à das línguas.» (Darwin, 1872: 22).

A profundidade destas expressões mímico-emotivas parece-lhe tal que «os movimentos expressivos (...) revelam os pensamentos e intenções dos outros com mais verdade do que as palavras, que podem mentir.» (Darwin, 1872: 359). E Darwin acentua, a par com as dificuldades de descrição das mímicas, a imediatez da empatia que leva a reconhecê-las como idênticas e significantes, tanto na forma como na função, em todos os grupos humanos: 
«Ninguém, julgo, poderá descrever rigorosamente uma expressão ressentida ou reservada; ainda assim, muitos observadores são unânimes em aceitar que estas expressões podem reconhecer-se nas várias raças de homens.» (Darwin, 1872: 355). E logo, procurando encontrar enquadramento e explicação teórica para estas observações: «Esforcei-me por mostrar em pormenor que todas as principais expressões exibidas pelo homem são as mesmas pelo mundo fora. Este dado é importante, por trazer um novo argumento a favor da descendência de todas as raças a partir de um único ramo progenitor, que deve ter sido quase completamente humano na forma e em boa parte do psiquismo, antes do período em que as raças divergiram umas das outras.» (Darwin, 1872: 355). E conclui: «Vimos como o estudo da teoria das expressões confirma, em parte, a conclusão de que o homem provém de alguma forma precedente de animal, e sustenta a minha convicção da unidade específica ou subespecífica das várias raças.» (Darwin, 1872: 360).

Voltemos, enfim, à figura de Wallace e ao momento e à decisão patética em que optou por excluir o cérebro humano do processo geral de evolução variacional selectiva. Essa decisão, esse percalço, retiraram-lhe em definitivo a aura formidável de imenso cientista, ombreando quase com Darwin, e remeteram-no desde então para o domínio obscuro da teologia natural. Ora, há que reconhecer que tal decisão foi em parte movida por um desígnio anti-racista, decerto inserido nas suas preferências ideológicas socialistas. No seu tempo, de resto, Wallace pertencia a uma restrita minoria de cientistas que se opunham à ideologia racista prevalecente. Assim, sendo os cérebros humanos subtraídos, na sua formação, à história natural evolutiva dos antepassados (ideia pasmosa na sua incongruência, para quem fora co-descobridor da própria teoria da evolução por selecção natural!), todos os grupos humanos seriam equivalentes em possibilidades inventivas de cultura e linguagem e, sobretudo, todos os homens seriam equivalentes em capacidades e iguais em direitos, ao nascerem.

Estes factos, esta controvérsia suscitada perante a genealogia e a diversidade dos seres humanos, ilustram a que ponto a ciência, ao aproximar-se do Homem - qualquer que seja a entidade assim entendida (e sobre ela não há consenso) - sofre a acção deformadora de poderosas forças colectivas, ideológicas, sociais, religiosas, que fazem interferir os jogos de interesses (eles próprios camuflados sob as convicções de grupos, e afeiçoados dentro do 'Espírito do tempo') com os critérios de prova. Esse é o principal ponto vulnerável das chamadas ciências humanas. Em cada momento da história 
das ideias flutua a convicção de que podemos enfim ajuizar do trabalho dos cientistas do passado, sorrir das suas interpretações e cedências, afeiçoadas às ideias dominantes. Puro mal-entendido: o preconceito permanece, e os cientistas do futuro tecerão sobre nós idênticos comentários críticos.

\section{Referências bibliográficas}

Darwin, C. 1871. The Descent of Man, and Selection in Relation to Sex. vol. I. London, John Murray.

Darwin, C. 1988. Charles Darwin's Beagle Diary, R.D. Keynes, ed. Cambridge, Cambridge University Press.

Darwin, C. 1998 [1872] The Expression of the Emotions in Man and Animals. Introduction, afterword and commentaries by Paul Ekman. London, Fontana Press.

Eibl-Eibesfeldt, I. 1979. Human ethology: concepts and implications for the sciences of man. The behavioral and brain sciences, 2: 1-57.

Ekman, P., Friesen, W. 1977. Nonverbal behaviour. In: Ostwald, P. (ed.) Communication and Social Interaction. New York, Grune \& Stratton: 221-229.

Wallace, A. R. 2007. Borneo, Celebes, Aru, London (Penguin Books / Great Journeys): extracts from The Malay Archipelago (1986).

Artigo recebido a 17 de Março de 2010 e aceite a 3 de Junho de 2010. 